\title{
Research on Protective Area of Exploiting Lower Protective Coal Seam and its Feasibility
}

\author{
Wang Kai ${ }^{1}$, Li Peng $^{1, *}$,Wei Jianping ${ }^{2}, \mathrm{Li} \mathrm{Bo}^{2}$ and Wang Fuzhong ${ }^{3}$ \\ ${ }^{1}$ Faculty of Resources and Safety Engineering, China University of Mining \& Technology (Beijing), Beijing, 100083-China \\ ${ }_{2}^{2}$ School of Safety Science and Engineering, Henan Polytechnic University, Jiaozuo, 454000-China \\ ${ }^{3}$ School of Electrical Engineering and Automation, Henan Polytechnic University,Jiaozuo ,China,454003;
}

Received December 2013; Accepted February 2014

\begin{abstract}
Based on the reasonable consideration of the role of the second main stress in D-P criterion, the distribution of stress and deformation with the method of finite difference was simulated. And the stress relief angles along incline and strike according to the rules of stress and deformation were obtained. Then the protective area resulted from exploiting the lower protective coal seam were acquired. The results show that the stress relief angles along incline are 75.5 and 77.7 degrees, the ones along strike are 78.4 and 83.5 degrees in the sense of protection when the advancing distance is $300 \mathrm{~m}$. But the real effective protective area is much smaller. The largest degree of stress relief locates in the protected coal seam corresponding to the upper and middle of the working face. According the simulation results and the water inrush coefficient method of effective water-resisting seam, the water inrush risk area of lower protective coal seam was divided, and the feasibility of exploiting protective coal seam was analysed and judged. Research results are of certain guidance and reference significance in the layout of mining and gas extraction for the similar coal mines.
\end{abstract}

Keywords: Lower Protective Coal Seam, Protective Area, Numerical Simulation, D-P Criterion, Feasibility

\section{Introduction}

With the increasing depth of mining, gas content and gas pressure increases gradually [1], [2], and there is a growing risk on coal and gas outburst [3], [4], [5]. Exploiting the protective coal seams is a preferred regional outburst prevention measure for effective control of coal and gas outburst [6], [7]. The mechanism of the protective coal seam exploitation is that it can release the gas pressure and elastic potential energy of protected coal seam, and increase the permeability of protected seam. So its key is to determinate the effective protective area and extract the stress relief gas [8], [9], [10]. Especially the planning and designing of the latter is often based on the former one. Thus the reasonable determination of effective protective area is the foundation of exploiting the protective coal seam. In order to eliminate the threat on mine safety due to the high in-stiu stresses and high gas content conditions, it is necessary to analyze the feasibility of exploiting protective coal seam for these coal mines lack of mining protective coal seam before. The traditional method is to rely on the relevant technical specifications or standards to determine, but not all the mines have the same actual production conditions. So numerical simulation emerges as the times require, it does not rigidly adhere to a fixed standard, even it can be based on actual states and makes different responses.

As a mechanical analysis tool, FLAC ${ }^{3 \mathrm{D}}$ which is three dimensional finite difference computer codes for mechanics

\footnotetext{
*E-mail address: lipeng0718@126.com.cn

ISSN: 1791-2377 @ 2014 Kavala Institute of Technology. All rights reserved.
}

applications has been widely accepted by academic and engineering circles [11], [12], [13]. Utilizing this unique tool, numerical simulation analysis on exploiting the lower protective coal seam in a coal mine of Shanxi province was carried out, the stress distribution, deformation law and real valid protective area of protected seam were attained. In this coal area, so far is there not mined as the protective seam. Hence research on caving space movement and fracture evolution of overlying strata in the process of exploiting protective seam has theoretical significance on the evaluation of protective seam mining feasibility, the effect of and the technological optimization of the stress relief gas drainage. In other words, the evaluation of the effective protective area not only affects the accuracy of outburst prevention measures, but also connects with the forecasting the appropriate spatial and temporal region of gas drainage.

Furthermore, No.2 coal seam is the main mined seam in this coal mine, and the measured maximum gas content is $7.2 \mathrm{~m}^{3} / \mathrm{t}$, the maximum gas pressure is $0.72 \mathrm{MPa}$. Since the rock pressure gradually became greater after entering the deep mining stage, the dynamic characteristics phenomenon of coal and gas outburst seriously intimidate the normal production safety and the replacement of the working faces. And there are two coal seams under No.2 coal seam. Especially the thickness of No.6 coal seam is up to $1.1 \mathrm{~m}$, so there are very good protective seam mining conditions. If No.6 coal seam is mined as the protective seam, the protective effect on the upper coal seams will be realized, then the gas pressure and the stress of rock mass will be relieved, as we all known, the permeability coefficient will be greatly improved, finally the most thorough security on 
the prevention of coal and rock dynamic disasters and gas management will be provided.

\section{Numerical Simulation Model and Instability Criterion}

Before the lower protective seam mining was numerically simulated with FLAC $^{3 \mathrm{D}}$, the numerical model and the instability criterion were firstly determined.

\subsection{Object of Simulation}

There are twelve coal seams in this coal mine, where No.2 and 6 seams are the main mined coal seams. The average thickness of No.2 and No.6 seams is $3.2 \mathrm{~m}$ and $1.1 \mathrm{~m}$ respectively, the average angle of dip is 10 degrees, the space between No. 2 and No.6 seams is $30.8 \mathrm{~m}$. No.6 seam is the lower protective seam and No.2 seam is the protected seam. The No.6 mining area is determined as the main object of this numerical simulation.

\subsection{Model Sizes}

In order to establish a finite difference model and eliminate the effect of boundary restrictions, the boundaries of this model were confirmed according to the movement and deformation of the coal and rock affected by mining. Considering that the model should meet the needs of real application, the mining height of the protective seam is 1.1 $\mathrm{m}$, the simulation region of the working face is a body in the shape of a cuboid with dimensions $300 \mathrm{~m} \times 100 \mathrm{~m} \times 1.1 \mathrm{~m}$ and an oblique angle of 10 degrees. Consequently, the size of the model is $500 \mathrm{~m} \times 300 \mathrm{~m} \times 160 \mathrm{~m}$.

\subsection{Boundaries}

$\mathrm{X}$ and $\mathrm{Y}$ are the two horizontal directions and $\mathrm{Z}$ is the vertical direction. The surrounding displacement boundary is horizontally restricted; the bottom displacement boundary of the model is restricted in all the directions. According to the measured data of the original in-situ stress, the upside stress boundary of the model is a symmetrical load of $8.9 \mathrm{MPa}$ and the horizontal stress in the $\mathrm{X}$ and $\mathrm{Y}$ directions is confirmed as 8.2 and $7.4 \mathrm{MPa}$ respectively.

\subsection{Calculation Parameters}

According to testing results of rock mechanics parameters and mine geological datas, physical mechanical parameters of the coal and rock in this model are shown in Tab. 1, where $\rho$ is the destiny, $\mathrm{E}$ is the elastic modulus, $\mu$ is the possion ratio, $\mathrm{C}$ is the cohesive strength, $\varphi$ is the internal friction angle and $R_{m}$ is the tensile strength.

Table 1. Physical mechanical parameters of the model

\begin{tabular}{ccccccc}
\hline Strata & $\begin{array}{c}\rho \\
\left(\mathrm{Kg} / \mathrm{m}^{3}\right)\end{array}$ & $\begin{array}{c}\mathrm{E} \\
(\mathrm{GPa})\end{array}$ & $\mu$ & $\begin{array}{c}\mathrm{C} \\
(\mathrm{MPa})\end{array}$ & $\begin{array}{c}\varphi \\
\left({ }^{\circ}\right)\end{array}$ & $\begin{array}{c}\mathrm{R}_{\mathrm{m}} \\
(\mathrm{MPa})\end{array}$ \\
\hline Sandy mudstone & 2450 & 22.00 & 0.30 & 5.00 & 34.00 & 1.25 \\
Sandstone & 2800 & 30.00 & 0.23 & 9.38 & 42.00 & 2.38 \\
No.2 seam & 1400 & 2.00 & 0.34 & 2.50 & 32.00 & 0.50 \\
Fine sandstone & 2600 & 25.00 & 0.28 & 6.25 & 35.00 & 1.75 \\
No.6 seam & 1400 & 2.00 & 0.34 & 2.50 & 32.00 & 0.50 \\
Fine sandstone & 2600 & 26.00 & 0.26 & 7.50 & 37.00 & 2.13 \\
Limestone & 2650 & 30.00 & 0.24 & 8.75 & 40.00 & 2.50 \\
\hline
\end{tabular}

\subsection{Model grid}

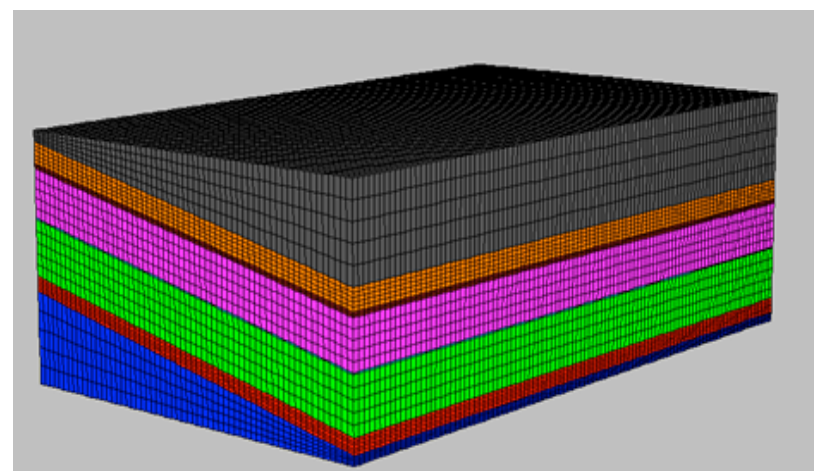

Fig. 1 Finite difference grid of the model

With the command "model null" of the FLAC ${ }^{3 \mathrm{D}}$ software in this numerical simulation, the working face is excavated. There are 209473 grid-points and 198000 zones in this numerical simulation model. Based on the advancing distance, the excavation range was determined. The finite difference grid of the model is described in Fig. 1.

\subsection{Instability Criterion}

The coal and rock mass are considered ideal elastic-plastic bodies, where D-P criterion was adopted as the instability criterion, in order to consider the role of the second main stress, and the criterion can be described as follows:

$\mathrm{f}=\alpha \mathrm{I}_{1}+\mathrm{J}_{2}^{-1 / 2}-\mathrm{K}=0$

where $I_{1}$ is the first invariant of stress and $I_{1}=\sigma_{1}+\sigma_{2}+\sigma_{3}\left(\sigma_{1}\right.$, $\sigma_{2}$ and $\sigma_{3}$ are respectively the max., middle and min. main stresses), $\mathrm{J}_{2}$ is the second invariant of the stress deviator and parameter $J_{2}=\left[\left(\sigma_{1}-\sigma_{2}\right)^{2}+\left(\sigma_{2}-\sigma_{3}\right)^{2}+\left(\sigma_{3}-\sigma_{1}\right)^{2}\right] / 6, \alpha$ is a related test constant and $\alpha=2 \sin \varphi / 3^{1 / 2}(3-\sin \varphi), \mathrm{K}$ is another related test constant and $\mathrm{K}=6 \mathrm{C} \cos \varphi / 3^{1 / 2}(3-\sin \varphi), \varphi$ is the internal friction angle, and $\mathrm{C}$ is the cohesive strength.

\section{Simulation results}

Based on the instability criterion, the lower protective seam in numerical simulation model was respectively excavated to $100 \mathrm{~m}, 200 \mathrm{~m}$ and $300 \mathrm{~m}$, and then all these simulation results were compared with the initial data before excavation.

3.1 Distribution of Stress in Protected Seam along Incline The vertical stress distribution of the mining area after advancing working face for $300 \mathrm{~m}$ is described in Fig. 2.

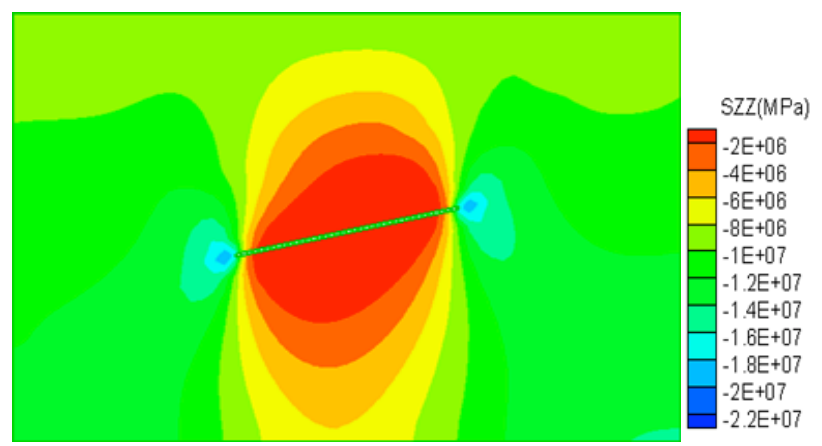

Fig. 2 Stress field of the mining area along incline 
It can be seen from Fig. 2 that the stress of the surrounding strata of the working face is concentrated in different degree. The stress of the surrounding coal and rock strata of mining area was redistributed after mining the lower protective seam. And the stress in the roof and floor strata of the goaf were relieved. It is because that excavation makes the roof and floor strata move, deform and fracture, floor heave, the stress transfer, and then the reduction and concentration area of the stress are formed in a certain range. The maximum principal stress of strata above the central goaf has greatly decreased than the original in-sti stress, which explains that it began to appear a certain degree of stress relief in this region. Therefore, it is propitious to the development of the fracture and the improvement of the permeability. Thus, the fracture in this region is more developed, the permeability of the coal and rock mass is much larger than the original one, and this is the reason that often put the drainage holes in this region.

In order to further explain the stress relief effect, the monitor points in protected seam were set in the numerical simulation. The relief effect of the stress in the protected seam along incline can be described in Fig. 3 .

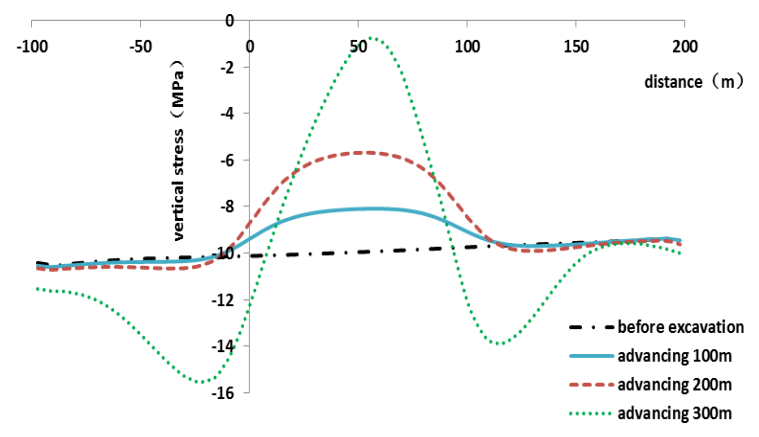

Fig. 3 Stress relief of monitor points in protected seam along incline

The $0 \mathrm{~m}$ shown in Fig. 3 represents the position of the downside of travelling roadway. And the $100 \mathrm{~m}$ represents the position of the upside of return airway. The horizontal axis represents the distance away from the downside of travelling roadway, and the vertical axis means vertical stress. It can be seen from Fig. 3 that the stress of monitor points in No. 2 coal seam changes obviously before and after the excavation. Near the middle location along incline, the degree of stress relief is the biggest, but it becomes the concentration of stress near the boundaries of the goaf. The stress relief curve shows as parabolic. Meanwhile, the changes of the maximum principal stress in No. 2 coal seam shows as regular symmetrical distribution, and there only appeared larger variation in the corresponding position of goaf and boundaries, the region outside of the mining area did not change basically.

When the protective seam was put along to $100 \mathrm{~m}$, the principal stress in the No.2 seam above the goaf was reduced, but the stress relief degree is relatively smaller, in other words, the protection effect on the protected seam of the protective seam is much less. Along with the increase of the advancing distance, within a certain range, the maximum principal stress of the protective seam is further reduced due to the movement of overlying strata above the goaf. With the increasing of advancing distance of working face, the stress concentration degree of the mining area boundaries increases continually and the stress relief degree of the upper coal seam above the goaf also continues to strengthen. This is because that after mining lower protective seam, the stress of overlying strata transfers to the rock out of the goaf to bear. As the advancing distance increases, this effect is more and more obvious. So is the concentration effect of the vertical stress near the boundaries of the goaf.

\subsection{Distribution of Stress in protected seam along Strike}

What is shown in Fig. 4 is the distribution of the vertical stress along strike of the protected seam along with the working face advancing $300 \mathrm{~m}$.

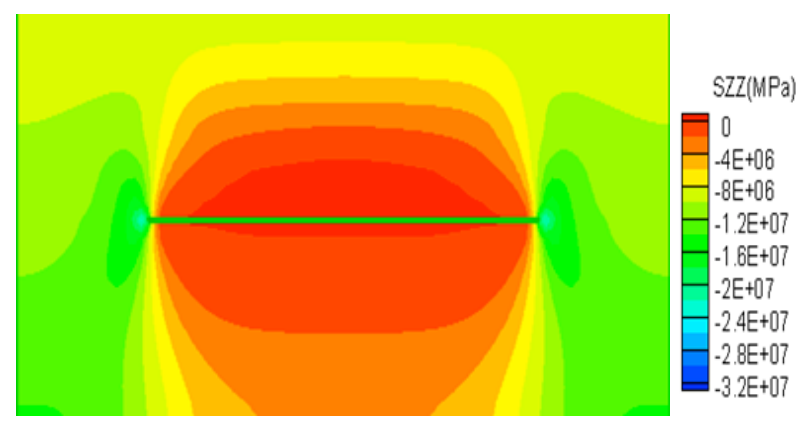

Fig. 4 Stress field of the mining area along strike

It is seen from Fig. 4 that the vertical stress of strata surrounding No. 2 seam along strike changed mostly as the one along incline. But the stress relief scope is much larger. Due to the continuous subsidence, the vertical stress in some areas of No.2 seam above the goaf of No.6 seam reduced further when the working face was advanced for $300 \mathrm{~m}$. The vertical stress in some areas decreased to $0 \mathrm{MPa}$, indicating that these areas were completely relieved.

Meanwhile, the stress of the areas in front of the working face in the protective seam turned concentrated. So did the areas behind the working face. As a result, the elastic potential of the protected seam was released in a larger range, and the stress field of the surrounding strata of the protective seam showed as the shape of saddle. The specific effect of stress relief with different advancing distances is shown in Fig.5.

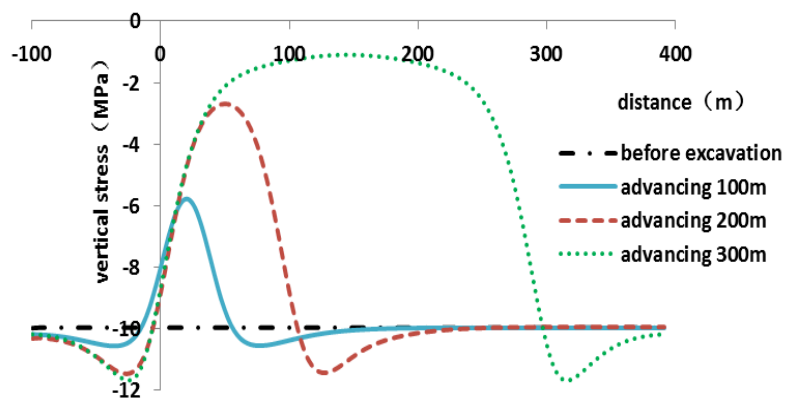

Fig. 5 Stress relief of monitor points in protected seam along strike

The $0 \mathrm{~m}$ shown in Fig. 5 represents the position of the open-off cut of the lower protective seam. And the $300 \mathrm{~m}$ represents the position of the mining stop line of the protective seam. The horizontal axis represents the distance away from the open-off cut, and the vertical axis means vertical stress. The changes in the vertical stress of the protected stress were distributed along strike symmetrically 
in the shape of "W". According to different stress state, the protected seam can be divided into five regions which are separately a virgin stress region, a stress concentration region, a stress relief region, a stress concentration region and again a virgin stress region. This partitioning is equally suitable for the one along incline.

\subsection{Deformation of Protected Seam}

Obviously, the deformation of the protected coal seam can be obtained by the expression as follows:

$\varepsilon=\Delta \mathrm{z} / \mathrm{T}$

Where $\varepsilon$ is the deformation of the protected coal seam, $\Delta z$ represents the difference of normal displacement between the roof and floor strata of the protected coal seam, and $\mathrm{T}$ is the initial thickness of the protected coal seam.

Through the analysis on the displacement of the roof and floor of the protected seam, the final results of the deformation of the protected seam can be shown in Fig. 6 and Fig.7, respectively.

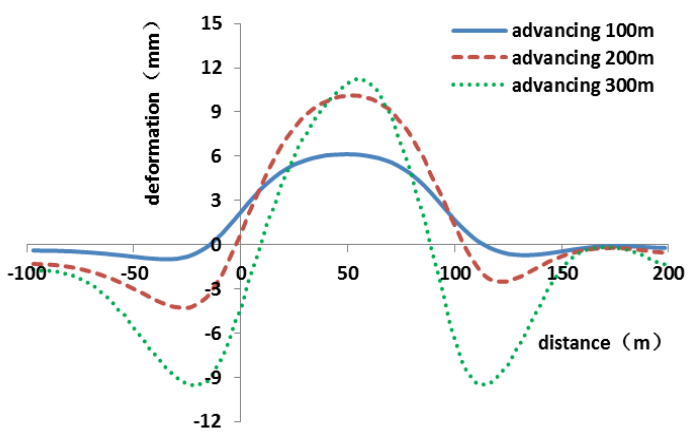

Fig.6 Deformation of the protected seam along incline

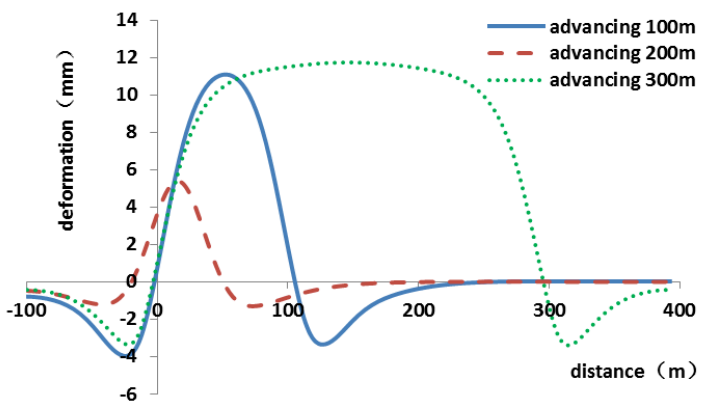

Fig.7 Deformation of the protected seam along strike

The deformation of the roof and floor strata of the protected seam is described in Fig. 6 and Fig. 7 when the working face was respectively advanced for $100 \mathrm{~m}, 200 \mathrm{~m}$ and $300 \mathrm{~m}$. From these figures, it is shown that the upper part of the goaf in the protected seam became bulged after mining the protective seam. The upper part corresponding to the back of the open-off cut and the front of the work-ing face was compressed. The max expansion up to $11.73 \mathrm{~mm}$ appeared in the middle of the protected layer. Taking into account that the thickness of coal seam 2 is $3.2 \mathrm{~m}$, so the maximum swelling deformation is $0.37 \%$ and this value has exceeded the critical value in the "Regulations on Coal and Gas Outburst Prevention in China", which is $0.3 \%$. Thus, the protected seam was obtained the effective protection in a certain range of areas.

At the same time, by monitoring the process of numerical simulation, the movement rule of protected seam was shown as the sinking phenomenon in the process of mining. The scale of the exploiting the protective seam has a great influence on the protected seam. In the early mining stage, mining protective seam has less affected on the deformation of the protected seam. But along with the advance of working face, the swelling deformation of the protected seam increases gradually and tends to be stable. And in a certain range that locates in the goaf behind the working face, the swelling deformation of the protected seam has kept at a greater value as the stress has not recovered. Due to the stress redistribution of the overlaying strata resulted from the excavation of protective coal seam, the protected seam is compressed within a certain range. Then the amount of compression tends to be stable while the advance distance climbs up to a certain value. A maximum compression deformation is existed in the coal column of the protected seam above the open-off cut in the protective coal seam. Along with the working face in the protective seam advancing forward, the deformation law of protected seam can be divided into five regions which are separately a virgin state, compression, expansion, compression, and again a virgin state. What needs to be emphasized is that the maximum swelling deformation appeared in the central goaf, showing that the fracture of coal mass was developed, which is conducive to the gas migration and the pressure relief gas drainage.

\section{Determination of the Protective Area}

As usual, the protective area along incline can be confirmed by two aspects. One is by stress and the other is by deformation. With the help of the cloud chart of the stress distribution which is obtained from the numerical simulation, construct a linear tangent from the edge of the coal wall to the original field stress isogram, and the slope of this tangent is just the tangent value of the stress relief angle. But the stress in the protective area divided by the stress relief angles utilizing this method is less than the original field stress. So this protective area is not the real effective one where the coal and gas outburst hazard is eased. The real effective protective area is often less than this stress relief area.

\subsection{Protective Area along Incline}

From the technical criterion of protective coal seam exploitation, the protective area of protected seam along incline should be confirmed by the stress relief angles. Fig.3 shows that when the protective seam was advanced for $300 \mathrm{~m}$, the distance between the downside boundary of the protective area along incline and the travelling roadway of the protective seam was $7.69 \mathrm{~m}$. Meanwhile, the distance between the upper boundary of the protective area along incline and the return airway of the protective seam was $6.5 \mathrm{~m}$. Hence the downside and upper stress relief angles of the protected seam were confirmed as 75.5 and 77.7 degrees respectively.

As we all know, the effective critical value of swelling deformation in the "Regulations on Coal and Gas Outburst Prevention in China" is $0.3 \%$. So it can be obtained from Fig. 6 that the distance between the downside boundary of the effective protective area along incline and the travelling 
roadway of the protective seam was $40.3 \mathrm{~m}$ and the distance between the upper boundary of the protective area along incline and the return airway of the protective seam was $33.1 \mathrm{~m}$. So the downside and upper stress relief angles of the protected seam were confirmed as 36.5 and 39.7 degrees respectively.

From these two different aspects, it can be found that not all the stress relief area is the effective one. The real effective protective area is much smaller than all the stress relief areas.

\subsection{Protective Area along Strike}

Likewise, the protective area of protected seam along strike can also be confirmed by the stress relief angles. Fig.5 shows that when the protective seam was advanced for $300 \mathrm{~m}$, the distance between the left boundary of the protective area along strike and the open-off cut of the protective seam was $6.3 \mathrm{~m}$. Meanwhile, the distance between the right boundary of the protective area along strike and the mining stop line of the protective seam was $3.5 \mathrm{~m}$. Hence the left and right stress relief angles of the protected seam were confirmed as 78.4 and 83.5 degrees respectively.

Similarly, it can be obtained from Fig. 7 that the distance between the left boundary of the effective protective area along strike and the open-off cut of the protective seam was $42.5 \mathrm{~m}$ and the distance between the right boundary of the protective area along strike and the mining stop line of the protective seam was $45.9 \mathrm{~m}$. So the left and right stress relief angles of the protective seam were confirmed as 35.5 and 33.4 degrees respectively.

In a word, the effective protective area is not as large as the stress relief area. So it can not completely eliminate the risk of coal and gas outburst only with the exploiting the protective seam. So gas drainage is often assisted, and the reasonable arrangement of advanced distance and time of mining are also important.

\section{Feasibility analysis on lower protective seam exploiting}

It can be found from the complex mine geological conditions that the faults are very developed in this mine, $\mathrm{K}_{5}, \mathrm{~K}_{4}$ and $\mathrm{K}_{2}$ limestone strata locates below No.6 seam and the floor water pressure is very big, the Ordovician limestone water pressure is much bigger, so deep mining has certain influence on the No.2 coal seam. Meanwhile, many small water inrush phenomena in the process of exploiting No.2 seam had happened. After the No.6 coal seam was mined as the protective seam, all details need to be analyzed such as whether the stress relief of floor strata will connect lower limestone water and induce the water inrush or not. Therefore, it is of great practical significance to study the feasibility of lower protective seam exploiting from the view of preventing the water inrush. As long-wall mining is advanced along, the failure zone of the coal and rock seams is enlarged, the strain increased correspondingly, and the fissures developed in larger degree, certainly resulting in the formation of water inrush channels.

\subsection{Water inrush risk assessment of protective seam}

For the reasonable evaluation of water inrush risk in this coal mine, utilizing the water inrush coefficient method of effective water-resisting seam with the help of the data from numerical simulation results, water inrush risk assessment on the floor of lower protective coal seam was carried out. This method focuses on the disturbance and destruction of water-resisting seam of mining pressure, but also relates to many factors such as lithology, geological structure. Water inrush coefficient represents that the water pressure that one meter of effective water-resisting seam can be born. And it is prone to water inrush when the water pressure that waterresisting seam can be born than critical pressure values.

The calculation formula of the water inrush coefficient is as follows:

\section{$\mathrm{T}_{\mathrm{s}}=\mathrm{P} /\left(\mathrm{M}-\mathrm{C}_{\mathrm{p}}\right)$}

Where $T_{\mathrm{s}}$ is the water inrush coefficient and the unit of $\mathrm{T}_{\mathrm{s}}$ is $\mathrm{MPa} / \mathrm{m}, \mathrm{P}$ is the bearing water pressure of waterresisting seam and the unit of $\mathrm{P}$ is $\mathrm{MPa}, \mathrm{M}$ is the thickness of water-resisting seam the unit of $M$ is meter, $C_{p}$ is the failure depth due to the stress disturbance and the unit of $C_{p}$ is meter.

The parameter selection of the bearing water pressure in the floor of coal seam is based on the hydrogeological exploration design report and the hydrological dynamic observation results from the surface hydrological holes. So the bearing water pressure in the floor of coal seam was acquired. The bearing water pressure in the floor strata of protective seam owing to the $\mathrm{K}_{2}$ limestone water is from $1.384 \mathrm{MPa}$ to $3.184 \mathrm{MPa}$. The bearing water pressure in the floor strata of protective seam owing to the Ordovician limestone water is from $1.944 \mathrm{MPa}$ to $4.403 \mathrm{MPa}$.

The determination of the thickness of water-resisting seam is according to the data from hydrological holes and some coal holes. So the thickness of water-resisting seam used in the calculation of $\mathrm{K}_{2}$ limestone aquifer is $35.5 \mathrm{~m}$, and the one of Ordovician limestone aquifer is $76.5 \mathrm{~m}$. The failure depth due to the stress disturbance is obtained by the simulation results, taking into account the safety, so the maximum failure depth is $20.32 \mathrm{~m}$.

The calculation of water inrush coefficient is borrowed by the regulation of "Provisions for mine water prevention and control in China". Usually, the water inrush coefficient in the block where the floor is tectonically damaged is less than $0.06 \mathrm{MPa} / \mathrm{m}$, while the water inrush coefficient in the normal block is less than $0.1 \mathrm{MPa} / \mathrm{m}$. Thus, the water inrush coefficient of the $\mathrm{K}_{2}$ limestone aquifer should be from $0.091 \mathrm{MPa} / \mathrm{m}$ to $0.210 \mathrm{MPa} / \mathrm{m}$, and the one of the Ordovician limestone aquifer is from $0.030 \mathrm{MPa} / \mathrm{m}$ to $0.078 \mathrm{MPa} / \mathrm{m}$.

According to the provisions for mine water prevention and control in China, the regionalizing principle of water inrush area in this coal mine can be worked out as below. Based on the water inrush coefficient, geological conditions and other factors, the water inrush level can be divided into three gradients in this coal mine.

I. Water inrush security zone. It is located in the area above the water level of limestone aquifer, not existing water inrush risk resulted from the bottom limestone strata.

II. Water inrush threatening zone. It is located in the area below the water level of limestone aquifer, while the water pressure of the water-resisting seam in the normal section is greater than the actual pressure values, and the water inrush coefficient is less than $0.1 \mathrm{MPa} / \mathrm{m}$, but there exists the probable water inrush threat near the faults or other weak sections.

III. Water inrush hazardous zone. It is located in the area below the water level of limestone aquifer, and the water pressure of the water-resisting seam in the normal section is less than or equal to the actual pressure values, while the water inrush coefficient is more than or equal to $0.1 \mathrm{MPa} / \mathrm{m}$. 
Therefore, when water inrush coefficient is $0.10 \mathrm{MPa} / \mathrm{m}$, the elevation of the $\mathrm{K}_{2}$ limestone seam and the protective seam is $253.78 \mathrm{~m}$ and $289.28 \mathrm{~m}$, respectively. So the area in which the elevation of coal seam floor is less than $289.28 \mathrm{~m}$ is the $\mathrm{K}_{2}$ limestone water inrush hazardous zone, the area in which the elevation of coal seam floor is greater than $289.28 \mathrm{~m}$ is the $\mathrm{K}_{2}$ limestone water inrush threatening zone, and all the mined range in the protective seam is the Ordovician limestone water inrush threatening zone.

\subsection{Feasibility assessment of protective seam exploiting} According to the assessment of the water inrush risk on the floor strata of lower protective seam, the whole No.6 coal seam has always been endured the water inrush threat in the mining process, and the range of water inrush risk zones of No.6 coal seam is larger. The actual situation that the fault structures are well developed in the coal seam increases water inrush risk, and it is necessary to take the control measures for preventing the water inrush in the mining process, so it will increase the costs of mining, which leads to the economic benefits decline.

Furthermore, the thickness of No.6 coal seam is only $1.1 \mathrm{~m}$, if exploiting the protective coal seam, it will excavate the a great deal of rock mass and increase the difficulty of exploitation. Therefore, from the viewpoint of water inrush prevention and cost saving, No.6 coal seam is better not to be exploited as the protective coal seam.

\section{Conclusions}

Through the numerical simulation, the changes in the maximum main stress of the protected coal seam were distributed symmetrically in the shape of a hump. Its process of change includes five stages, which are separately a virgin stress region, a stress concentration region, a stress relief region, a stress concentration region and again a virgin stress region. And along with the working face in the protective seam advancing forward, the deformation law of protected seam can be divided into five regions which are separately a virgin state, compression, expansion, compression, and again a virgin state.

The upper and downside boundaries of the protective layer along incline had pressure relief angles of 77.7 and 75.5 degrees. The strike pressure relief angle at the working face of the protective layer was ranged from 78.4 and 83.5 degrees.

Because the effective protection scope is much smaller than the stress relief scope, therefore, in order to completely eliminate the risk of coal and gas outburst, it is necessary to strength gas extraction and schedule mining time and advanced distance on the basis of exploiting the protective coal seam.

The whole No.6 coal seam has always been endured the water inrush threat in the mining process, and the range of water inrush risk zones is much larger. From the view of water inrush prevention and cost saving, No.6 coal seam is better not to be exploited as the protective coal seam.

\section{Acknowledgments}

The authors gratefully acknowledge the support of National Natural Science Foundation of China (No. 51174212), the Fundamental Research Funds for Central Universities (2010QZ05 \& 2013QZ01), the Special Research Foundation for Doctorate Disciplines in Universities of China (20120023110006), and the Open Funds of State Key Laboratory Cultivation Base for Gas Geology and Gas Control-Henan Polytechnic University (WS2012A01 \& WS2013A03). Doctoral Fund of Henan Polytechnic University(B2011-064)

\section{References}

1. Yuanping, C., Qixiang, Y., "Application of safe and high-efficient exploitation system of coal and gas in coal seams", Journal of China University of Mining \& Technology, 32(5), 2003, pp. 471475.

2. Yuanping, C., Qixiang, Y., "Development of re-gional gas control technology for Chinese coal mines", Journal of Mining \& Safety Engineering, 24(4), 2007, pp. 383-390. (in Chinese)

3. Baohong, S., Jianzhong, L., Hong, Z., "The technical measures of gas control in China coal mines", Journal of China Coal Society, 32(7), 2007, pp. 673-679.

4. Qianting, H., Shining, Z., Xinquan, Z., "Mechanical mechanism of coal and gas outburst process", Journal of China Coal Society, 33(12), 2008, pp. 1368-1372.

5. Yuanping, C., Jianhua, F., Qixiang, Y., "Development of gas extraction technology in coal mines of China", Journal of Mining \& Safety Engineering, 26(2), 2009, pp. 127-139. (in Chinese)

6. Biming, S., Qixiang, Y., Shining, Z., "Numerical simulation of fardistance rock strata failure and deformation caused by mining protecting stratum", Journal of Mining \& Safety Engineering, 33(3), 2004, pp. 259-263. (in Chinese)

7. Biming, S., Zegong, L., "Numerical simulation of the upper coal and rock deformation characteristic caused by mining protection stratum", Journal of China Coal Society, 33(1), 2008, pp. 17-22.
8. Guozhong, H., Hongtu, W., Xiaogang, F., et al. "Gas pressure investigation on protection region of up-protective layer of pitching oblique mining", Journal of China University of Mining \& Technology, 37(3), 2008, pp. 328-332.

9. Guozhong, H., Hongtu, W., Xiaohong, L., et al. "Optimization design on extracting pressure-relief gas of steep-inclined upprotective layer with pitching oblique mining", Journal of China University of Mining \& Technology, 34(1), 2009, pp. 9-14.

10. Zhigang, Y., Hongtu, W., Guozhong, H., et al. "Numerical simulation for protection scope of upper protective seam in steeply inclined multi-coal seam", Journal of China Coal Society, 34(5), 2009, pp. 594-598.

11. Hang, L., Jiangguo, Y., Huaxing, Z., et al. "Development and application of constitutive model of jointed rock mass damage due to mining based on FLAC ${ }^{3 \mathrm{D}}$,, China Journal of Rock Mechanics and Engineering, 27(3), 2008, pp. 572-579.

12. Yongchun, D., Jianhua, W., Bin, X., "Three-dimensional numerical analysis of braced excavation based on FLAC ${ }^{3 \mathrm{D}}$,, Journal of Shanghai Jiaotong University, 43(6), 2009, pp. 976-980.

13. Shengang, L., Wen, Z., Cheng, W., et al. "Research on grouting effect on tunneling with FLAC ${ }^{3 \mathrm{D}}$,, Journal of Northeastern University (Natural Science), 31(3), 2010, pp. 440-443. 